\title{
PENSANDO NOVAS PRÁTICAS EM TERAPIA OCUPACIONAL, SAÚDE E TRABALHO
}

\author{
NEW PERSPECTIVES IN OCCUPATIONAL \\ THERAPY, DISCUSSING HEALTH AND WORK
}

\author{
Selma Lancman $^{(1)}$, Maria Isabel Garcez Ghirardi ${ }^{(2)}$
}

\begin{abstract}
LANCMAN, S.; GHIRARDI, M. I. G. Pensando novas práticas em terapia ocupacional, saúde e trabalho. Rev. Ter. Ocup. Univ. São Paulo, v. 13, n. 2, p.44-50, maio/ago. 2002.

RESUMO: O presente artigo aborda as mudanças atuais nas relações de trabalho e a maneira como essas mudanças afetam a saúde mental e a vida dos trabalhadores. Discute novas perspectivas práticas e teóricas em Terapia Ocupacional no campo da saúde e trabalho.
\end{abstract}

DESCRITORES: Terapia Ocupacional/tendências. Saúde mental. Trabalho. Psicologia do trabalho.

$\mathrm{O}$ processo de globalização econômica atualmente em curso tem definido intensas transformações no mundo do trabalho. Inovações tecnológicas, mudanças na organização do trabalho e o surgimento de novas profissões em detrimento de outras, são alguns dos fatores que vêm contribuindo para que haja uma redefinição das relações entre capital e trabalho, levando empresas já existentes a se reorganizarem para se adequar a essa nova realidade.

Esse processo vem propiciando também uma mudança no perfil da classe trabalhadora favorecendo a diminuição da classe operária industrial paralelamente à expansão do trabalho no setor de serviços. Essas mudanças provocam um impacto nas relações trabalhoemprego, e a inserção no mercado de trabalho tende a assumir formas variadas através da terceirização de serviços e da oferta de trabalho autônomo, por exemplo.

Frente a isso, emprego, estabilidade, aposentadoria ou uma carreira profissional linear e progressiva, bem como direitos trabalhistas e proteção à saúde do trabalhador começam a ceder espaço a novas

\footnotetext{
(1) Docente do Curso de Terapia Ocupacional da FMUSP, Doutora em Saúde Mental pela Universidade Estadual de Campinas, Pós-doutora em Psicologia do Trabalho pelo Conservatoire National des Arts et Metier, França.

${ }^{(2)}$ Docente do Curso de Terapia Ocupacional da FMUSP, Doutora em Psicologia Social pelo Instituto de Psicologia da Universidade de São Paulo.

Endereço para correspondência: Rua Cipotânea, 51. Cidade Universitária, São Paulo, SP. CEP: 05306-000. e-mail: pepag@usp.br, lancman@usp.br
} 
relações no mercado de trabalho. O desemprego, o subemprego e o trabalho informal tornam-se permanentes e estruturais nas sociedades atuais, favorecendo relações de trabalho precárias que terminam por atingir também as condições de trabalho e saúde daqueles que estão ainda empregados. Essa lógica de restrição de oportunidades leva trabalhadores assalariados a cederem à precarização das condições de trabalho e às perdas de direitos trabalhistas que dela decorrem, deixando aos trabalhadores a escolha entre um mau trabalho ou trabalho nenhum.

Essas mudanças provocam um impacto na vida de indivíduos que são obrigados a conviver com lógicas de mercado extremamente mutantes, criando uma situação de constante instabilidade e de ameaça que é vivenciada como um mal inevitável dos tempos modernos, cuja causalidade é atribuída ao destino, à economia ou ainda às relações sistêmicas (DEJOURS, 1999, p. 20).

A precarização das relações de trabalho provoca, segundo Dejours (1999, p.20), quatro principais conseqüências para os trabalhadores, a saber: a intensificação do trabalho e o aumento do sofrimento subjetivo daqueles que permanecem trabalhando; a neutralização da mobilização coletiva contra o sofrimento, a dominação e a alienação no trabalho; a estruturação de estratégias defensivas em que todos precisam resistir e "não podem fazer nada" pelo sofrimento alheio e, por fim, frente à ameaça de demissão, o individualismo, o "cada um por si".

Inúmeras pesquisas e intervenções têm sido realizadas visando tanto à melhoria da produtividade, quanto às condições e à organização do trabalho, mas ainda são poucas aquelas que se preocupam com o conteúdo simbólico do trabalho, com as relações subjetivas do trabalhador com a sua atividade, com o sofrimento e desgaste gerado pelo trabalho e com os seus efeitos sobre a saúde física e mental dos indivíduos.

É importante ressaltar o papel central que o trabalho assume na constituição da identidade individual, e sua implicação direta nas diversas formas de inserção social dos indivíduos. Castel (1998, p. 532) ao discutir o processo social de desfiliação, observa a relação direta que se estabelece entre o processo de precarização das relações de trabalho e a vulnerabilidade social a que o individuo está exposto como decorrência desse processo. Haveria uma tendência crescente à vulnerabilidade social de indivíduos que se vêm na contingência da precarização do trabalho, devido à importância que as relações de trabalho assumem na constituição da identidade individual.
Constituição da identidade é aqui compreendido como um processo que se desenvolve ao longo de toda a vida do indivíduo, e que está vinculado à noção de alteridade. É a partir do "olhar do outro" que nos constituímos como sujeitos, é na relação com o outro que nos reconhecemos num processo de busca de semelhanças e diferenças. São as relações cotidianas que permitem a construção da identidade individual e social e é partir de trocas materiais e afetivas que o sujeito vai estar ao longo de toda a vida constituindo sua singularidade, em meio a diferenças.

Na vida adulta, o espaço do trabalho será o palco privilegiado dessas trocas, aparecendo como o mediador central da construção, do desenvolvimento e complementação dessa identidade individual. Assim, o trabalho tem fundamental importância para a vida psíquica e a valorização do trabalho vai significar um status positivo ao indivíduo. Além disso, é necessário lembrar que o desenvolvimento da identidade social estará fortemente pautado pelas relações de trabalho que o indivíduo desenvolve. Nesse sentido o trabalho pode ser visto como fundamental na constituição de redes de relações sociais e de trocas afetivas e econômicas que estão na base da vida cotidiana das pessoas.

O trabalho permite o confronto entre mundo externo e mundo interno do trabalhador. $\mathrm{O}$ mundo objetivo, com suas lógicas, seus desafios, suas regras e seus valores vão entrar em conflito com a singularidade de cada trabalhador, fazendo com que o confronto entre relações e organizações do trabalho por um lado e, por outro lado o mundo interno e subjetivo do trabalhador seja gerador de sofrimento psíquico. Há uma contradição central entre a lógica das empresas, voltada para o lucro e para a produtividade, e a lógica do indivíduo que é contraditório, tem angústias, desejos, medos e que busca manter sua saúde mental em meio a essa complexidade de relações.

Assim, se por um lado o mundo do trabalho será gerador de sofrimento na medida em que confronta as pessoas com desafios externos, por outro lado, o trabalho é também a oportunidade central de crescimento e de desenvolvimento psicossocial do adulto. Ou seja, se o trabalho leva ao sofrimento, esse mesmo trabalho pode se constituir numa fonte de prazer e de desenvolvimento humano do indivíduo tanto quanto de adoecimento. Dessa forma, fica evidente que o trabalho e as relações que nele se originam nunca podem ser tomados como um espaço de neutralidade subjetiva ou social.

Por outro lado, é nas relações que ocorrem a partir do trabalho que se permite o desenvolvimento da 
identidade e a transformação do sofrimento em prazer, a partir do olhar do outro e da valorização decorrente desse olhar. Quando o reconhecimento do trabalho não existe, a desvalorização conseqüente atinge outros espaços da vida cotidiana dos trabalhadores, contaminando o tempo do não trabalho. Neste sentido, o trabalho deve ser entendido como um continuum que se estende para além de seu espaço restrito e influencia outras esferas da vida.

Entender a influência da organização do trabalho na qualidade de vida, na saúde mental, na geração de sofrimento psíquico, no desgaste e no adoecimento dos trabalhadores é de fundamental importância para a compreensão e para a intervenção em situações de trabalho que podem levar a diversas formas de sofrimento.

Apreender e compreender as relações de trabalho, exige mais do que a simples observação, mas sobretudo, exige uma escuta voltada a quem executa o trabalho, pois este implica em relações subjetivas menos evidentes que merecem ser desvendadas. Para apreender o trabalho em sua complexidade é necessário entendêlo e explicá-lo para além do que pode ser visível e mensurável é necessário que se considere também a qualidade das relações que ele propicia.

A escuta que propomos deve ser realizada de forma coletiva e desenvolvida a partir de um processo de reflexão realizado com o conjunto de trabalhadores. Acreditamos que é somente a partir da reflexão sobre o próprio trabalho que o indivíduo é capaz de se reapropriar da realidade de seu trabalho e da relação entre seu trabalho e sua saúde. Essa mesma reflexão é que pode permitir aos trabalhadores a mobilização que vai impulsionar as mudanças necessárias para tornar o trabalho mais saudável.

Se de um lado, o mundo do trabalho se modifica e muda a realidade dos que nele estão envolvidos, de outro, diversas profissões e teorias se ocupam em estudá-lo e em propor alternativas organizacionais que possam melhorar a qualidade de vida, humanizar as relações de trabalho e repensar o fator humano nos processos tecnológicos nos seus diferentes aspectos.

Acreditamos que o incremento de pesquisas na área de Saúde e Trabalho só pode se dar a partir da congregação e da combinação de esforços de diversas profissões e de diferentes teorias e metodologias. As pesquisas nesta área são um desafio interdisciplinar, que requer esforços múltiplos para entender a complexidade da nova realidade e propor abordagens inovadoras, contribuindo para o desenvolvimento de propostas que levem a intervenções transformadoras do trabalho.

Nessa perspectiva, o conceito de prevenção demanda um novo olhar a partir da compreensão de que, a prevenção de doenças e sofrimento geradas no trabalho, deve se dar a partir de mudanças na organização do trabalho. Dessa forma, essas novas abordagens estariam se contrapondo às correntes que acreditam que é possível prevenir doenças ocupacionais a partir de mudanças parciais e paliativas no espaço do trabalho, mas que não consideram o caráter coletivo e global da problemática que envolve sobretudo a identidade do trabalhador.

Pensar uma intervenção voltada à prevenção, implica em pensar ações com potência para mobilizar micro transformações sociais. A mudança da qualidade do trabalho não pode resultar de prescrições produzidas por consultores externos alheios ao cotidiano dos trabalhadores, mas devem ser consequência de um processo de reflexão realizado pelos próprios envolvidos que poderão transformar o trabalho graças a uma intensa e gradativa atividade de reconstrução de regras, normas e valores (DEJOURS et al., 1994).

Nesse contexto, deve-se repensar a mudança do perfil das doenças relacionadas ao trabalho, bem como a gênese dessas doenças e a gravidade que elas representam tanto com relação à quantidade de acometidos, quanto em relação ao processo gradativo de exclusão que elas podem representar. Deve-se, também, repensar propostas de intervenção tanto em situações de trabalho visando a diminuir a incidência destes acometimentos mórbidos, quanto alternativas para os trabalhadores já acometidos.

Dentre as principais doenças relacionadas às novas organizações de trabalho, destacamos as Doenças Ósteo-Musculares Relacionadas ao Trabalho/Lesões por Esforços Repetitivos (DORT/LER) e as doenças mentais relacionadas ao trabalho, que vêm ganhando proporções alarmantes do ponto de vista da saúde pública, dos gastos públicos e dos problemas sociais que envolvem (CODO; ALMEIDA, 1995; RIBEIRO, 1997; LIMA et al., 1997; LANCMAN; SIQUEIRA, 1999).

No Brasil, a partir dos anos 80, a notificação de casos de DORT/LER aumentou de maneira significativa. Inicialmente identificada como uma doença ligada ao setor de serviços o número de casos registrados não cessa de crescer em diversos setores industriais, tais como: metalurgia, eletro-eletrônicos, produtos alimentares etc. As DORT/LER bem como outras formas de sofrimento e adoecimento no trabalho ainda são objeto de discussão no que tange ao estabelecimento de nexo causal com o trabalho.

Diagnosticar segundo os parâmetros objetivos tradicionalmente utilizados pela medicina, tais como, exames de laboratório complementares e uma avaliação objetiva e universal dos sintomas que fazem parte das síndromes, dificultam que se qualifique a dor ou o 
sofrimento do trabalhador de forma a estabelecer o início e o fim dos agravos e sua possível relação com as condições de trabalho.

É importante destacar também, a dificuldade em estabelecer uma fronteira que permita discriminar entre sofrimento e dor, enquanto sensações passageiras às quais todos estamos submetidos, e enquanto o início de patologias graves. É sutil a variação entre tristeza, angústia e ansiedades passageiras, dores pontuais $\mathrm{e}$ depressões patológicas, estados de angústia e ansiedades mórbidos e dores indicativas de processos de adoecimento em fases iniciais.

Entre os fatores objetivos e subjetivos que explicam o aumento das DORT/LER e das doenças mentais ligadas ao trabalho citamos alguns aspectos que, embora contribuam de forma diferente no surgimento destas patologias, precisam ser considerados quando buscamos uma compreensão global da problemática, são eles: intensificação e sobrecarga daqueles que permaneceram no mundo do trabalho, aumento de movimentos repetitivos, ritmo acelerado imposto pela máquina, posturas corporais inadequadas e anti-naturais, sobrecarga de determinados grupos musculares, por exemplo. Citamos, ainda, os fatores ligados à organização do trabalho, tais como a separação entre o planejamento e a execução das atividades, as dificuldades ligadas à divisão e relação entre os trabalhadores, como por exemplo a hierarquia rígida, as relações de poder autoritárias, a impossibilidade do trabalhador contribuir na transformação do trabalho, a pressão de chefia, a desconfiança e a competição entre pares, além da obrigação de realizar horas extras.

A dificuldade de mensurar e diagnosticar os problemas mentais e o sofrimento ligado ao trabalho, segundo os parâmetros usualmente utilizados pela medicina, prejudica o estabelecimento do possível nexo causal existente entre adoecimento psíquico e trabalho. Além disso, a falta de amparo legal freqüentemente se torna um empecilho aos trabalhadores para a obtenção de licenças médicas associadas ao sofrimento psíquico ou, quando se obtém as licenças, estas acabam por comprometer a imagem do trabalhador frente ao grupo, devido ao estigma que a doença mental carrega. Assim, é possível que o trabalhador vivencie uma dor física que pode ser diagnosticada como DORT/LER e com isso conseguir um afastamento legal para situações de grande sofrimento geradas por ambientes de trabalho muito tensos. Este sofrimento, por vezes, dadas as circunstâncias do ambiente do trabalho, não pode ser expresso, reconhecido ou nomeado, a não ser através de uma dor física.

\section{A PRÁTICA DA TERAPIA OCUPACIONAL EM SAÚDE DO TRABALHADOR}

Os Programas de Saúde do Trabalhador (PST) ou Centros de Referência em Saúde do Trabalhador (CRSTs) surgiram no final do regime militar, com o crescimento dos movimentos populares e o fortalecimento dos sindicatos de trabalhadores. $\mathrm{Na}$ cidade de São Paulo, os CRSTs surgiram em resposta à reivindicação dos trabalhadores e sindicatos e norteavam-se pelos princípios do Sistema Único de Saúde.

Embora não se ocupassem diretamente dos acidentados de trabalho, restringindo sua ação aos portadores de doenças relacionadas ao trabalho, já continham, em seus princípios, pressupostos da vigilância e intervenção em empresas visando ao estudo de postos, de ambientes e de condições de trabalho com a participação dos sindicatos e do Ministério Público. "A estratégia para implantação do Programa foi estabelecer, inicialmente, unidades especializadas que funcionassem como pólos articuladores das ações de saúde do trabalhador na rede local de saúde (...). Desde a implantação, as ações programáticas dos Centros de Referência em Saúde do Trabalhador (CRST) estão voltadas à assistência, à vigilância e às ações de ensino e pesquisa (OLIVEIRA; UDIHARA, 2002).

Apesar do avanço que os CRSTs significaram, sua evolução foi insuficiente no sentido de promover a interação entre ações individuais e coletivas. Transformaram-se, numa alternativa assistencial individual ao adoecimento no trabalho (mesmo quando os atendimentos eram realizados em grupo), mantiveram-se com freqüência distanciados do SUS e suas ações não conseguiram congregar a assistência com a vigilância. Foi a partir dessa constatação que a Secretaria de Saúde do Município de São Paulo passou a reformular estes serviços no sentido de superar e melhorar o atual modelo de atenção.

Os CRSTs são compostos por equipes com profissionais de diversas áreas, entre eles, o terapeuta ocupacional. Os terapeutas ocupacionais inseridos nessas equipes puderam ampliar sua prática para outros níveis de atenção, tais como: intervenção direta em situações de trabalho através de ações de vigilância, atendimento individuais e/ou em grupos de reflexão com trabalhadores portadores de doenças ligadas ao trabalho, mas que ainda se mantinham empregados (SIQUEIRA; QUEIROZ, 2001) ou ainda, na busca de alternativas para os que perderam o emprego. Essa ampliação do alcance de ações práticas trouxe para os terapeutas ocupacionais o desafio de buscar embasamento teórico em áreas nas quais o debate estava mais avançado. 
Houve então a aproximação de outras áreas tais como, saúde coletiva, ergonomia, psicologia social e do trabalho e psicodinâmica do trabalho, que passaram a integrar os currículos de cursos de graduação e pósgraduação em Terapia Ocupacional no Brasil. Esta ampliação do campo de atuação e a incorporação de novos conteúdos teóricos nos coloca diante da necessidade de desenvolver e de formular teorias que possam agregar conhecimentos específicos da Terapia Ocupacional.

A Terapia Ocupacional tradicionalmente propõe a inclusão dos indivíduos no trabalho como objetivo último do processo de reabilitação. Neste sentido, os modelos de análise de atividades desenvolvidos, em consonância com a noção de que a reabilitação é um processo individual, procuravam adaptar e adequar os indivíduos ao trabalho ou vice-versa, ou ainda, adaptar máquinas e instrumentos para que os indivíduos com deficiências oriundas ou não do mundo do trabalho pudessem trabalhar. Esse modelo reducionista de reabilitação tem sido superado e outras teorias passam a enriquecer o debate de forma que a própria concepção do objeto da reabilitação passa por transformações trazendo uma compreensão das relações sociais implicadas nessa problemática.

Os terapeutas ocupacionais, ao alargarem seu campo de ação para a prevenção e para a intervenção em situações concretas de trabalho, começam a reconhecer no seu instrumental de trabalho e na sua experiência profissional a influência de diversos saberes que contribuem para o estabelecimento de um perfil profissional ímpar neste campo, quer seja pela sua experiência particular no uso e no estudo de atividades, quer seja pela maneira como apreende a complexidade e a singularidade dos indivíduos em sua relação com o trabalho (SIQUEIRA et al., 1996).

Dessa forma, diversos recursos tradicionais dos terapeutas ocupacionais na área de saúde e trabalho ganham uma nova dimensão e aplicação. Por exemplo, a análise de atividades que deixa de ser centrada no fazer individual e passa a abranger a compreensão de situações de trabalho tanto no âmbito organizacional quanto no que diz respeito às condições de trabalho. A utilização de atividades expressivas passa a integrar o universo de recursos facilitadores de dinâmicas de grupo ou de processos de reflexão grupal entre os trabalhadores. Além disso, a compreensão da interrelação entre as várias esferas ligadas à vida cotidiana do individuo está presente durante todo o processo de intervenção do terapeuta ocupacional quando se trata de saúde do trabalhador.

Entendemos, no entanto, que devemos aprofundar a reflexão entre terapeutas ocupacionais a fim de que possamos aprimorá-la seja em termos teóricos, seja em termos metodológicos. Isto significa considerar a importância do trabalho e sua influência em todos os âmbitos do viver, apontar para a construção de um novo modelo de intervenção na área voltado para uma abordagem mais preventiva e coletiva, para a compreensão da centralidade do trabalho na organização social e psíquica dos indivíduos e na determinação da qualidade de vida e tempo do não trabalho.

Vale lembrar que se entendemos o trabalho enquanto constitutivo do indivíduo e da sua identidade, não podemos pensar mudanças funcionais e parciais sem levarmos em conta a complexidade das relações que o mundo do trabalho implica, essa compreensão é essencial na busca de processos de transformação de situações de trabalho. Não se pode realizar mudanças paliativas, que desconsiderem os aspectos psicossociais envolvidos na saúde e no sofrimento psíquico dos trabalhadores.

Um dos aspectos mais relevantes da teoria dejouriana é a discussão a respeito dos mecanismos de defesa desenvolvidos individual ou coletivamente para enfrentar o sofrimento e os constrangimentos ligados ao trabalho. $\mathrm{O}$ adoecimento de um ou de vários trabalhadores traz como consequiência uma ameaça a esses mecanismos de defesa, fragilizando-os e desestabilizando-os, pois evidencia o caráter patologizante do trabalho. Dessa forma, os trabalhadores estabelecem uma estratégia defensiva diante do medo dos riscos a que estão expostos e tendem a culpar o próprio trabalhador pelo adoecimento (o indivíduo é fraco ou quebra mão, por exemplo), evitando com isso entrar em contato com os riscos do trabalho que realizam. Como vimos anteriormente, desenvolvem estratégias coletivas de silêncio de "não poder fazer nada pelo sofrimento alheio" e do individualismo.

A clínica do trabalho busca desenvolver o campo da saúde mental e trabalho, ligando a intervenção à pesquisa pautada pelos princípios da pesquisa-ação. Busca-se intervir em situações de trabalho, de atendimento e de reabilitação dos trabalhadores, além de compreender os processos psíquicos envolvidos e de formular hipóteses que representem avanços teóricos e metodológicos, reproduzíveis em outros contextos de trabalho. Assim, as intervenções devem procurar facilitar entre os trabalhadores a construção de um processo de reflexão sobre o próprio trabalho, permitindo uma apropriação e emancipação que conduzam a uma reconstrução coletiva do trabalho.

É dentro dessa perspectiva que pensamos avançar a constituição de um modelo clínico em terapia 
ocupacional no campo da saúde mental e trabalho que subsidie a atuação dos terapeutas ocupacionais em empresas, no tratamento de indivíduos acometidos por doenças ligadas ao trabalho e no retorno à atividade de trabalhadores afastados com restrições laborais. Para tanto é necessário estar atento aos diversos aspectos do trabalho apontados anteriormente e que consideramos essenciais neste tipo de abordagem, seja em caráter preventivo, de tratamento ou de reabilitação.

Os terapeutas ocupacionais começam a compor equipes nos Departamento de Saúde Ocupacional e nos Serviços de Segurança e Medicina do Trabalho das empresas e vêm colaborando na prevenção de agravos à saúde do trabalhador; afastamentos ou aposentadorias precoces; percepção de risco de acidentes do trabalho ou adoecimentos; avaliações funcionais; avaliação dos aspectos psíquicos do trabalho; conscientização dos efeitos do trabalho sobre o indivíduo; programas de realocação de indivíduos com restrições ocupacionais, decorrentes de processos de desgaste ou adoecimento no trabalho, em outras funções e postos de trabalho mais adequados a eles.

Do ponto de vista do tratamento propriamente dito, esses profissionais têm sido cada vez mais solicitados a atenderem sobretudo portadores de DORT/ LER, em serviços públicos, serviços-escola, CRSTs e clínicas privadas. Chamamos a atenção para a importância destes atendimentos que devem considerar as condições e a organização do trabalho enquanto determinantes do processo de adoecimento. Devem permitir ao trabalhador, não somente uma tomada de consciência mas, também, uma instrumentalização que venha mudar sua relação com o trabalho, fazendo do processo de tratamento um processo de participação que resulte em uma ação transformadora.

Nesse sentido, acreditamos que intervenções grupais sejam as mais adequadas para viabilizar esse processo, considerando que os atendimentos devem ocorrer por tempo determinado, evitando-se assim um processo de tutela e dependência dos trabalhadores em torno da atenção terapêutica.

O retorno ao trabalho daqueles que adoecem ou sofrem acidentes do trabalho deveria ser a ponta final do processo de reabilitação mas, na prática, se constitui em uma das questões mais desconsideradas no campo da saúde do trabalho, gerando um processo de exclusão dos trabalhadores vitimados. A terapia ocupacional vem discutindo a dificuldade de inserir no mundo do trabalho pessoas que por diversos motivos estão afastadas desse espaço social. A complexidade dessa questão é uma antiga preocupação dos terapeutas ocupacionais que têm buscado evitar visões reducionistas no que diz respeito aos aspectos psicossociais do trabalho.

Por outro lado sabe-se que a reintegração ao trabalho não ocorre em parte pela dificuldade dos técnicos responsáveis pela emissão dos laudos, de avaliar e medir a gravidade das seqüelas oriundas das doenças e arbitrar ou não pela manutenção do auxílio temporário ou vitalício. Dificuldade maior ainda é garantir os direitos do trabalhador para que uma vez retornando ao trabalho, o indivíduo não seja demitido ou "encostado" e que a volta ao trabalho não se transforme numa forma de exclusão tardia do acidentado.

A recuperação física e profissional e o retorno ao trabalho só poderão ocorrer se tivermos em conta os fatores que causaram o adoecimento e a necessidade de preveni-los. São diferentes etapas de um mesmo processo que é contínuo e único: cuidar do retorno ao trabalho do afastado, conhecer onde o processo de adoecimento começou e intervir nesse processo para prevenir novos acometimentos.

A reintegração dos trabalhadores com restrição laboral passa, ainda, por relações diversas, como as questões da desvalorização ou supervalorização da capacidade individual dos trabalhadores nos novos postos de trabalho, por uma necessária mudança de identidade e pelas relações com os demais trabalhadores que deverão assumir tarefas que os restritos não podem realizar, apenas para citar alguns aspectos.

Enfim, estamos diante de um campo complexo e inovador. Acreditamos que ainda há muito o que desenvolver tanto do ponto de vista teórico quanto metodológico. Considerar a complexidade dos aspectos apontados tanto em intervenções em postos de trabalho, no tratamento e na readaptação ao trabalho dos portadores de restrições laborais é um novo desafio dos terapeutas ocupacionais. No entanto, acreditamos que é a partir da nossa atuação nesta área e da reflexão que pudermos formular sobre essa prática que esse desafio pode ser enfrentado.

LANCMAN, S.; GHIRARDI, M. I. G. New perspectives in occupational therapy, discussing health and work . Rev. Ter. Ocup. Univ. São Paulo, v.13, n.2, p.44-50, maio/ago. 2002.

ABSTRACT: This article aims at discussing the current changes in work relationships and the way they affect the mental health and the daily life of workers. It also briefly describes new perspectives for progress in the area of Occupational Therapy health and work.

KEYWORDS: Occupational therapy/trends. Mental health. Work. Occupational psychology. 


\section{REFERÊNCIAS}

CASTEL, R. As metamorfoses da questão social, uma crônica do salário. São Paulo: Vozes, 1998.

CODO, W.; ALMEIDA, M. C. (Org.). Lesões por esforços repetitivos. Petrópolis: Vozes, 1995.

DEJOURS, C. Banalização da injustiça social. São Paulo: Fundação Getulio Vargas, 1999.

DEJOURS, C.; ABDOUCHELI, E.; CHRISTIAN, J.

Psicodinâmica do trabalho: contribuição da Escola Dejouriana à análise da relação prazer, sofrimento e trabalho. São Paulo: Atlas, 1994.

DEJOURS, C., DESSORS, D. MOLINIER, P. Comprende la résistance au chengement. Documents pour le médicine du travail. Paris: Institute National de Recherche et de Securité, Ministere du Travail - Direction des Relactions du Travail, 1994. p.112-8.

LANCMAN, S.; SIQUEIRA, A. R. La santé du travail et ergothérapie: à la recherche d'une méthodologie pour líntervention. J. D’Érgothérapie, v. 21, n. 1, p. 17-23, 1999.

LANCMAN, S.; SIQUEIRA, A. R.; QUEIROZ, M. F. F. Intervention dans le processus de travail d'un restaurant universitaire. Travailler, Rev. Int. Psychol. Psychodynamique Travail. (prelo).

Recebido para publicação: 16/01/002

Aceito para publicação: 04/03/2002
LIMA, M. E. A.; ARAÚJO, J. N. G.; LIMA, F. P. A. (Org.). L.E.R. Lesões por esforços repetitivos - dimensões ergonômicas e psicossociais. Belo Horizonte: Livraria e Editora Health, 1997.

OLIVEIRA, J. C.; UDIHARA, M. L. Construindo práticas, integrando áreas, vencendo desafios: a experiência do Centro de Referência em Saúde do Trabalhador da Lapa, Município de São Paulo. In: BORGES, L. H., MOULIN, M. G. B., ARAÚJO, M. D. Organização do trabalho e saúde: múltiplas relações. Vitória: Editora EDUFES/CCHN, 2002.

RIBEIRO, H. P. (Org.). LER: conhecimento, práticas e movimentos sociais. São Paulo: Faculdade de Saúde Pública, USP, Secretaria da Saúde do Estado de São Paulo, 1997.

SIQUEIRA, A. R.; QUEIROZ, M. F. F. Abordagem grupal em saúde do trabalhador. Mundo Saúde (São Paulo), v. 24, p. 4, 2001.

SIQUEIRA, A. R.; VIEIRA, A. O. G.; COSTA, M. J. T. O.; UDIHARA, M. L., ARAÚJO, R. C. S. S. Grupos de portadores de LER: atenção integral à saúde do trabalhadorcriando outras formas de intervenção no CRST-Lapa. In: SEMINÁRIO NACIONAL SOBRE LESÕES POR ESFORÇOS REPETITIVOS, 1., Brasília, 1996. (Mimeografado). 